\title{
NMR studies of the polyphotochromic behaviour of biphotochromic compounds
}

\author{
J. Berthet, ${ }^{1}$ S. Delbaere, ${ }^{1}$ V. Lokshin, ${ }^{2}$ A. Samat, ${ }^{2}$ J. C. Micheau, ${ }^{3}$ \\ and G. Vermeersch ${ }^{1, \dagger}$ \\ ${ }^{1}$ Laboratoire de Physique et LARMN, UMR CNRS 8009, Faculté de Pharmacie, \\ Université de Lille 2, BP 83, 59006 Lille cedex, France \\ ${ }^{2}$ GCOM2, UMR CNRS 6114, Université de la Méditerranée, 13288 Marseille Cedex 9, France \\ ${ }^{3}$ Laboratoire IMRCP, UMR CNRS 5623, Université Paul Sabatier, F-31062 Toulouse, France
}

\begin{abstract}
NMR spectroscopy has been used to investigate the photochromism of four biphotochromic molecules in both the spirooxazine and naphthopyran families. The thermal evolution of photoproducts and their structural identification made it possible to observe polyphotochromic behaviour: photocoloration, thermal bleaching, photo and thermal isomerisation, photoelectrocyclisation and thermochromism.
\end{abstract}

\section{INTRODUCTION}

Spirooxazines [1, 2] and naphthopyrans [3] are two families of compounds which have been widely investigated due to their excellent photochromic properties: good coloration under UV irradiation, fast thermal bleaching, and high fatigue resistance. These three criteria make them adequate candidates for industrial applications. Since the discovery of their photochromic behaviour $[4,5]$, many studies to modulate their properties by introducing various substituants have been reported [3, 6]. Guglielmetti's research group has been designing and synthesising biphotochromic molecules by linking two photochromic entities through different spacers [7].

As biphotochromic molecules constitute original systems, it was interesting to investigate their behaviour by NMR multinuclear spectroscopy. NMR has been already used to analyse successfully the photochromic behaviour of spirooxazine [8] and naphthopyran [9]. As reported in the precedent paper [10], this technique allows the unambiguous determination of the number of photoproducts and their structures. Moreover, kinetic studies are considerably improved by monitoring the changes occurring in the photoproducts and their interdependence. Indeed, their concentrations can be directly measured.

In the present paper then, we report the comparative study of the structural and kinetic determination of four biphotochromic molecules after UV irradiation: a binaphthopyran molecule joined through an ethane bridge (Chr-Et-Chr) and three other structures joined by a $\mathbf{Z}$ ethenic bridge: a binaphthopyran (ChrZ-Chr) [11], a bispironaphthooxazine (Spo-Z-Spo) [12],

†E-mail: gvermeer@pharma.univ-lille2.fr and a spirooxazine-naphthopyran (Spo-Z-Chr) [13] (see Scheme 1). The choice of these four systems was made to observe the effect of non-conjugated and conjugated bridges. Indeed, recent studies by spectrophotometrical methods have underlined polyphotochromic behaviour $[14,15]$. On the other hand, the presence of the ethenic spacer is expected to generate photoisomerisation and photocyclisation, due to the similarity with diarylethene-type molecules. Such systems have been the subject of intense investigations, as they open the way to novel applications in optical memories [16]. It is then essential to know the number, the structure and the thermal stability of photoproducts.

\section{EXPERIMENTAL DETAILS}

The synthesis of the molecules investigated: 1,2bis[3,3-di(4'-fluorophenyl)-[3H]-naphtho-[2,1-b]pyran5-yl]ethane (Chr-Et-Chr), the 1,2-bis[3,3-di(4'-fluorophenyl)-[3H]-naphtho-[2,1-b]pyran-5-yl]ethylene (ChrZ-Chr), the 1,2-bis(1,3,3-trimethylspiro[indoline-2,3'[3H]naphth-[2,1-b] [1,4]-oxazin-5'-yl)ethylene] (Spo-ZSpo), the 5'[2-(3,3-bis(4'-fluorophenyl)-[3H]naphto[2,1b]pyran-5-yl)vinyl][1,3,3-trimethylspiro[indoline-2,3'[3H]naphth[2,1-b] [1,4]oxazine] (Spo-Z-Chr) has been described in ref. [7].

The concentration of all the samples was $5 \cdot 10^{-3} \mathrm{M}$, in toluene- $d_{8}$.

Details about NMR experiments, irradiation set-up and procedure of kinetic data treatment have been previously described in ref. [17].

The degassing of the solutions to remove oxygen was performed by the technique of freeze-pump-thaw cycles (6 cycles) directly in the J. Young valve NMR sample tubes (Wilmad 507-JY-7). 
<smiles>Fc1ccc(C2(c3ccc(F)cc3)C=Cc3c(c(CCc4cc5ccccc5c5c4OC(c4ccc(F)cc4)(c4ccc(F)cc4)C=C5)cc4ccccc34)O2)cc1</smiles>

Chr-Et-Chr<smiles>CN1c2ccccc2C(C)(C)C12C=Nc1c(c(/C=C\c3cc4ccccc4c4c3OC3(C=N4)c4ccccc4C3(C)C)cc3ccccc13)O2</smiles>

Spo-Z-Spo<smiles></smiles>

Chr-Z-Chr<smiles>CN1c2ccccc2C(C)(C)C12C=Nc1cc3ccccc3c(/C=C\c3cc4ccccc4c4c3OC(c3ccc(F)cc3)(c3ccc(F)cc3)C=C4)c1O2</smiles>

Scheme 1. Structure of biphotochromic molecules under investigation.

\section{RESULTS AND DISCUSSION}

3.1. Behaviour at low temperature (228 K). After UV irradiation at $228 \mathrm{~K},{ }^{1} \mathrm{H}$ and ${ }^{19} \mathrm{~F}$ (if present) NMR spectra were recorded at regular time intervals. It was possible to observe the disappearance of the initial closed form and the appearance of new open structures. Following the evolution of intensities made it possible to correlate the different resonances belonging to one structure. 1 and 2D NMR experiments were performed to identify them. Mono and bi-opened structures were characterised. Photomerocyanines from naphthopyrans were proved to exist as only two transoid isomers: the Transoid-Cis (TC) and the Transoid-Trans (TT) (Figure 1).

In compounds Spo-Z-Spo and Spo-Z-Chr, the opening of the spirooxazine moiety leads to only one merocyanine: Trans-Transoid-Cis (TTC) (Scheme 2).

For the three compounds with an ethenic bridge, a Z-E isomerisation occurred leading to supplementary structures.

Thermal relaxation in the dark was followed by measuring signal intensities in the spectra at regular time intervals. From the plots of concentration vs. time (Figure 2), the rate constants of $\mathbf{T C} \rightarrow \mathbf{C h r}$ closing (Table 1 ) and TTC $\rightarrow$ Spo closing (Table 2) were determined for each corresponding compound.

Examination of this data clearly shows that the corresponding bleaching rate constants concord with those measured for a single naphthopyran
Table 1. Kinetic rate constants of naphthopyran photomerocyanines $\mathbf{T C} \rightarrow \mathrm{Chr}$ closing for various compounds in toluene at $228 \mathrm{~K}$.

\begin{tabular}{cc}
\hline Process & Rate constant $\left(\right.$ in $10^{-5} \mathrm{~s}^{-1}$ ) \\
\hline Chr-Et-TC $\rightarrow$ Chr-Et-Chr & 1.0 \\
TT-Et-TC $\rightarrow$ TT-Et-Chr & 1.1 \\
Chr-Z-TC $\rightarrow$ Chr-Z-Chr & 1.5 \\
TC-Et-TC $\rightarrow$ TC-Et-Chr & 1.6 \\
Chr-E-TC $\rightarrow$ Chr-E-Chr & 2.4 \\
TC-Z-TC $\rightarrow$ TC-Z-Chr & 2.8 \\
TTC-Z-TC $\rightarrow$ TTC-Z-Chr & 3.1 \\
Spo-Z-TC $\rightarrow$ Spo-Z-Chr & 3.2 \\
TC-E-TC $\rightarrow$ TC-E-Chr & 3.4 \\
TT-Z-TC $\rightarrow$ TT-Z-Chr & 4 \\
TT-E-TC $\rightarrow$ TT-E-Chr & 4.7 \\
\hline
\end{tabular}

Table 2. Kinetic rate constants of spirooxazine photomerocyanine TTC $\rightarrow$ Spo closing for various compounds in toluene at $228 \mathrm{~K}$.

\begin{tabular}{cc}
\hline Process & Rate constant $\left(\right.$ in $\left.10^{-4} \mathrm{~s}^{-1}\right)$ \\
\hline Spo-E-TTC $\rightarrow$ Spo-E-Spo & 0.8 \\
Spo-Z-TTC $\rightarrow$ Spo-Z-Spo & 0.8 \\
Chr-Z-TTC $\rightarrow$ Chr-Z-Spo & 0.8 \\
TC-Z-TTC $\rightarrow$ TC-Z-Spo & 1.1 \\
TTC-E-TTC $\rightarrow$ TTC-E-Spo & 1.2 \\
Chr-E-TTC $\rightarrow$ Chr-E-Spo & 1.3 \\
TTC-Z-TTC $\rightarrow$ TTC-Z-Spo & 1.5 \\
\hline
\end{tabular}



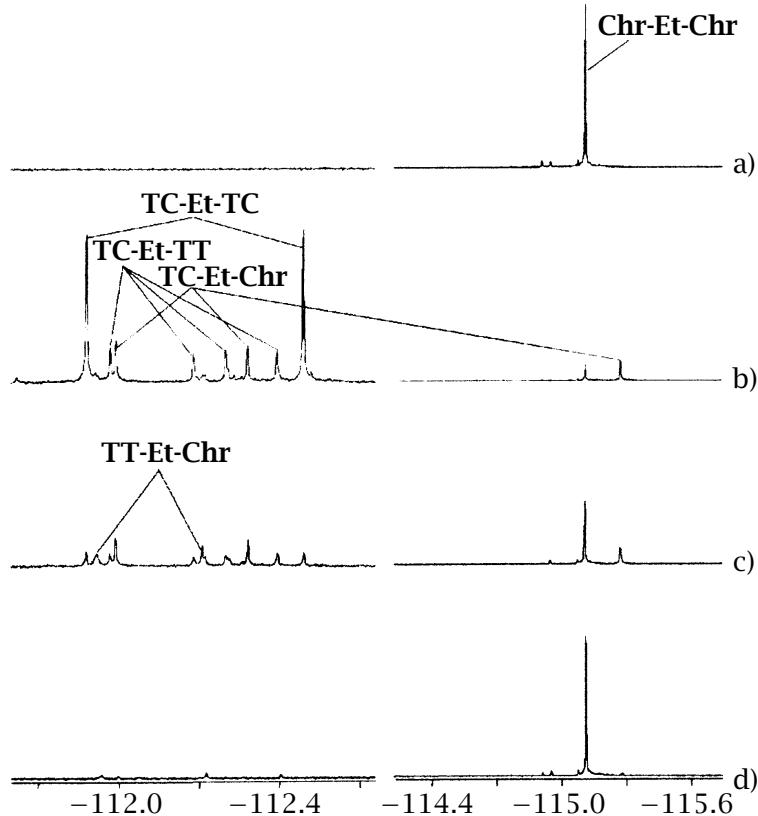

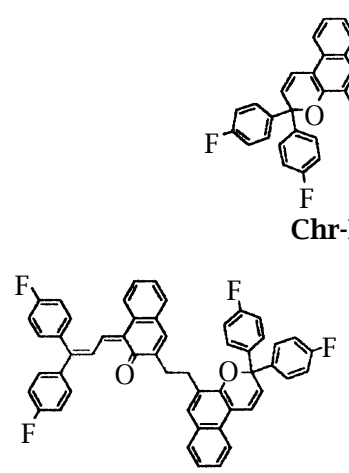

TC-Et-Chr

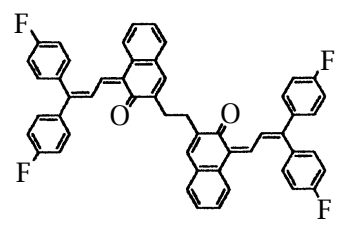

TC-Et-TC
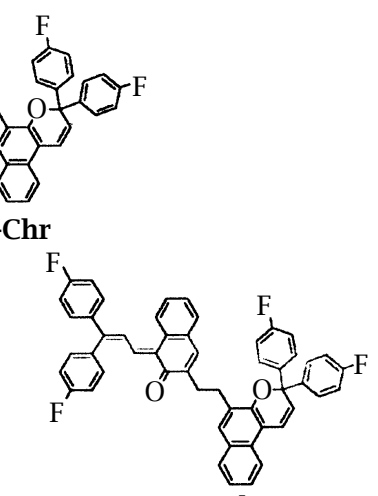

TT-Et-Chr

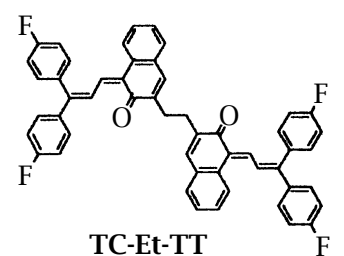

Figure $1 .{ }^{19} \mathrm{~F}$ spectra of $\mathrm{Chr}-\mathrm{Et}-\mathrm{Chr}$ at $228 \mathrm{~K}$ and structures of identified photoproducts. (a) before irradiation, (b) after $10 \mathrm{~min}$ of irradiation, (c) after $13 \mathrm{hrs}$ in the dark and (d) after $24 \mathrm{hrs}$ in the dark.

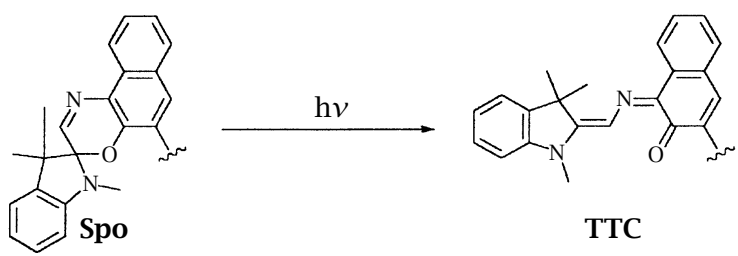

Scheme 2. Structure of the identified TTC isomer of the spirooxazine moiety.

$\left(\mathrm{k}_{\Delta}{ }^{228} \approx 5 \cdot 10^{-5} \mathrm{~s}^{-1}\right)$ or a single spirooxazine $\left(\mathrm{k}_{\Delta}{ }^{228} \approx\right.$ $2 \cdot 10^{-4} \mathrm{~s}^{-1}$ ) [10]. No significant thermal decay was observed for the naphthopyran TT isomer.

It is interesting to note the decay of symmetrical photomerocyanines, (for example: TC-Et-TC, TC-Z-TC, TC-E-TC, TTC-E-TTC and TTC-Z-TTC) which was not simultaneous for both of them, but consecutive, passing through structures with one closed and one open entity.

Consequently, the set of studies performed at low temperature showed the expected behaviour: UV irradiation produced an opening of the photochromic entities, leading to a distribution of isomers of photomerocyanines, which thermally returned to the initial closed form. In the case of molecules with Z-ethenic bridge (Chr-Z-Chr, Spo-Z-Spo and Spo-Z-Chr), photoisomerisation also occurred to yield the corresponding open E-isomers. These open E-isomers were then converted into closed E-molecules by the same mechanism.

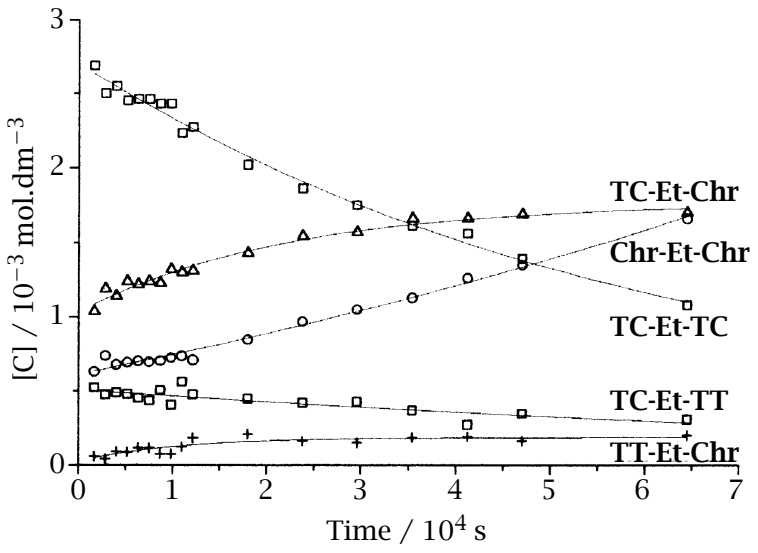

Figure 2. Examples of time-evolution concentrations of $\mathbf{C h r}$ Et-Chr after irradiation at $228 \mathrm{~K}$ (experimental points and fitted curves).

3.2. Behaviour at room temperature (293 K). At $293 \mathrm{~K}$, the kinetic rate constants of thermal bleaching of open spirooxazine and open naphthopyran are in the order of milliseconds. Nevertheless, spectrophotometric studies of molecules with ethenic spacer, in toluene solution, showed coloration persistency [14, 15]. Our aim was then to understand the origin of such a phenomenon.

Each of the biphotochromic molecules was irradiated at room temperature, and NMR spectra were obtained after UV irradiation. 


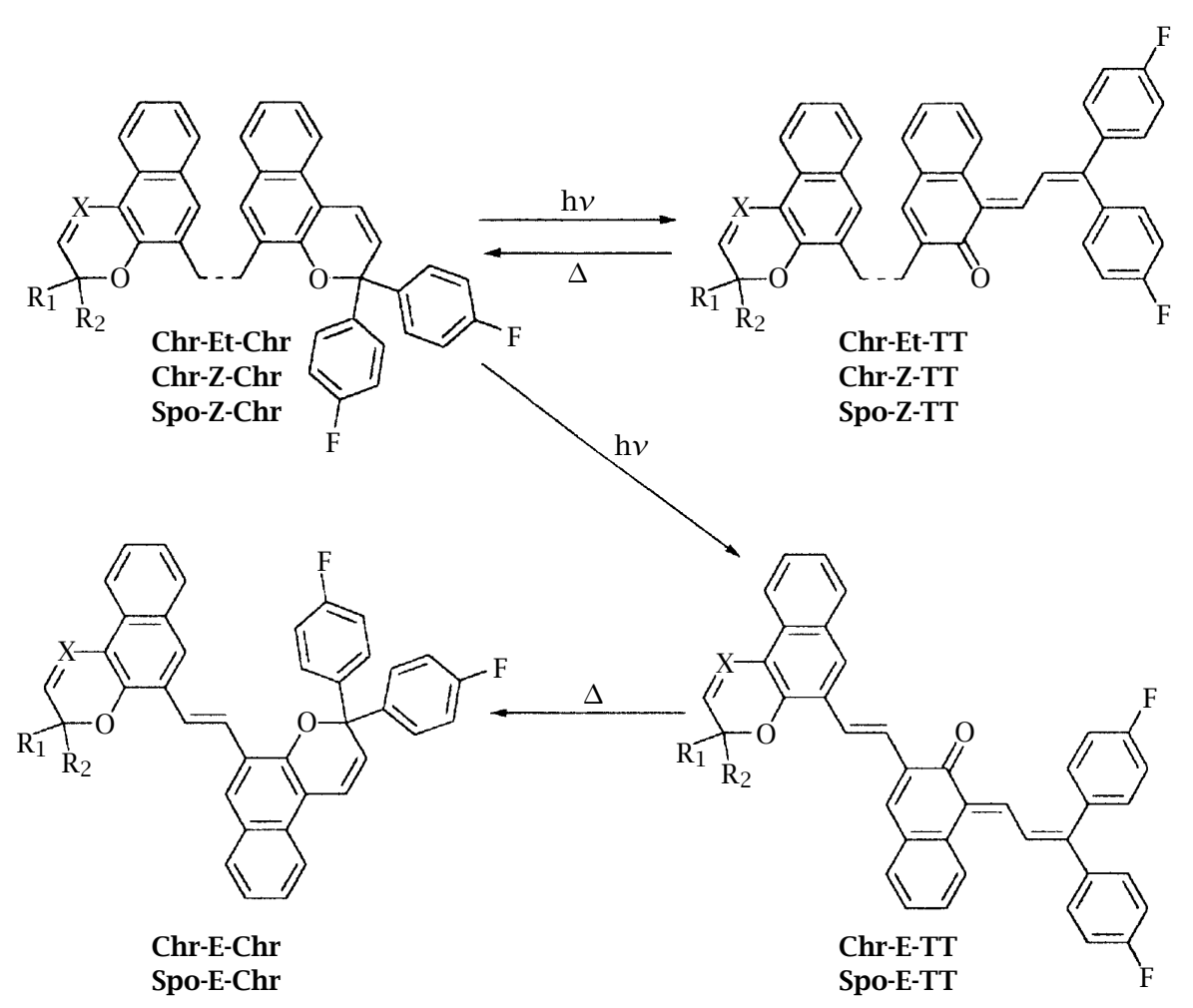

Scheme 3. General mechanism of the photochemically induced opening of a naphthopyran unit and thermal bleaching of the naphthopyran photomerocyanine TT in biphotochromic compounds at ambient temperature. $(\mathrm{X}=\mathrm{CH}$ for $\mathrm{Chr}, \mathrm{X}=\mathrm{N}$ for Spo, $\mathrm{R}_{1}$ and $\mathrm{R}_{2}=p$-fluoro-phenyl for $\mathrm{Chr}$ and spiroindoline for $\mathrm{Spo}$ ).

In the case of Chr-Et-Chr, only Chr-Et-TT was formed. Neither bi-opened structures, nor any TC photomerocyanines was detected. These observations are consistent with the fast bleaching of the TC openednaphthopyran at ambient temperature. In the same way, irradiation of molecules having at least one naphthopyran entity, Chr-Z-Chr and Spo-Z-Chr, was expected to produce photomerocyanines in TT configuration, whereas Spo-Z-Spo should not lead to open structures due to their very short half-life time. We detected the TT configurations of the naphthopyrans and other structures resulting for E-configuration of ethenic bond (Scheme 3).

Other structures were also produced, even when the spirooxazine derivative was irradiated and, each of these supplementary compounds was thermally stable. 1 and 2D NMR experiments were performed to characterise these new photoproducts. It was proved that UV irradiation produced an intramolecular electrocyclisation (D) of the diarylethene part of the Z-ethenic bridge and also the opening of photochromic entities. The molecules in open configuration were stabilised by this cyclization, thus explaining coloration durability. In addition, the thermochromism of the naphthopyran was underlined, because we observed the fast thermal opening of TC-D-Chr $\left(\mathrm{k}_{\Delta}^{293}=7 \cdot 10^{-4} \mathrm{~s}^{-1}\right)$ and TTC-D-
Chr $\left(\mathrm{k}_{\Delta}{ }^{293}=5 \cdot 10^{-4} \mathrm{~s}^{-1}\right)$ to TC-D-TC and TTC-D-TC, respectively.

Kinetic studies of the thermal behaviour of UVirradiated samples showed an evolution towards the formation of phenanthrenic products $(\mathbf{P h})$. Oxidation was accompanied by the reclosing of open entities and led to an irreversible loss of photochromic properties. This phenomenon was shown to take $\approx 6$ days with bispirooxazine (Spo-Z-Spo) and $\approx 13$ days with the biphotochromic molecule (Spo-Z-Chr), whereas it was extremely slow in the case of the bi-naphthopyran compound Chr-Z-Chr (only 3\% of oxidised photoproducts after 1 month). This degradation is not surprising, as dihydrophenanthrenic compounds are known to produce phenanthrenic structures [18].

As Spo-Z-Spo and Spo-Z-Chr were sensitive to the degradation pathway, both samples were reinvestigated in degassed solutions. After irradiation, dihydrophenanthrenic structures were produced and no or very little degradation was detected. For bispiroxazine Spo-Z-Spo, the initial molecule with closed spirooxazine entities and $\mathbf{Z}$ ethenic bridge was reformed by thermal relaxation in the dark.

However, in the case of Spo-Z-Chr, the retrieving of initial closed structure was extremely poor. Instead, the system evolved to equilibrium 


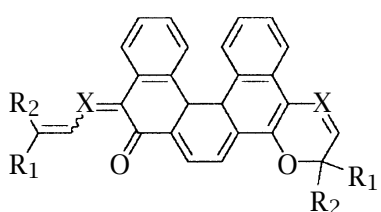

Mono-opening

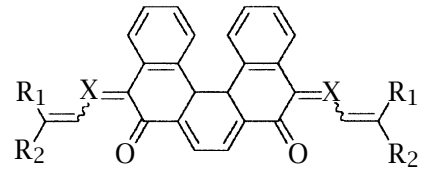

bi-opening

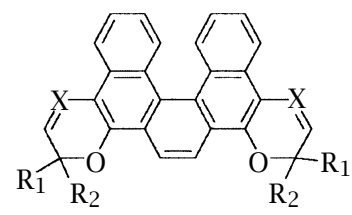

Phenanthrenic structure (Ph)

in dihydrophenanthrenic structures (D)

a)

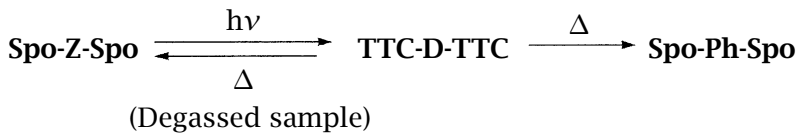

b)

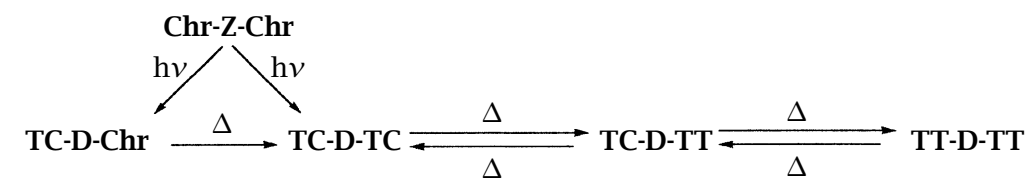

c)

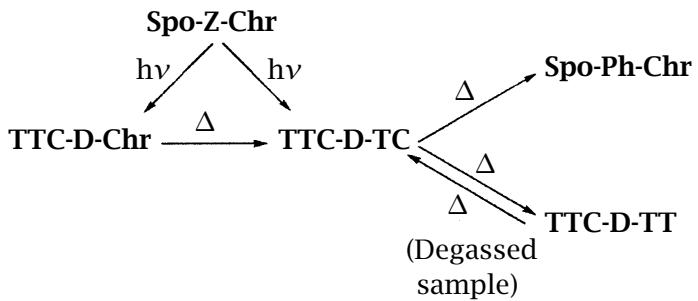

Scheme 4. Summary of observed reactions at $293 \mathrm{~K}$ for cyclised structures of (a) Spo-Z-Spo, (b) Chr-Z-Chr and (c) Spo-Z-Chr.

between TC and TT isomers of opened naphthopyran (TTC-D-TC $\leftrightarrow$ TTC-D-TT).

These observations are summarised in the following scheme (Scheme 4).

\section{CONCLUSION}

Four biphotochromic molecules have been investigated at low and ambient temperature, by NMR spectroscopy. Polyphotochromic behaviour has been reported. A classical opening-closing reaction was observed at $228 \mathrm{~K}$ : photomerocyanines resulting from the C-O breaking bond in the spirooxazine (TTC isomer) and naphthopyran (TC and TT isomers) were detected and characterised. The thermal evolution of pre-irradiated samples was followed to obtain the kinetic rate constants of bleaching. These parameters concord with values usually reported for spirooxazines and naphthopyrans. Mono- and bi-opened molecules were produced whichever the spacer (ethane or ethene), and bi-opened ones could be reclosed in two steps in the case of identi- cal photochromic entities: closing of one part followed by the reclosing of the other. No significant difference between kinetic rate constants determined for binaphthopyran molecules with ethane (Chr-Et-Chr) and ethenic junction (Chr-Z-Chr) was observed. For the unsymmetrical compound (Spo-Z-Chr), the decay of the spirooxazine part was faster than that of naphthopyran entity.

In addition, a $\mathbf{Z}$ to $\mathbf{E}$ photoisomerisation of ethenic spacer in Chr-Z-Chr, Spo-Z-Spo and Spo-Z-Chr was demonstrated. Mono- and bi-opened photomerocyanines in $\mathbf{E}$ configuration led to the formation of biclosed structures in E configuration (Chr-E-Chr, SpoE-Spo and Spo-E-Chr).

At room temperature, the behaviour was very different. Coloration was seen to be persistent, resulting from the thermal stability of photomerocyanines and was due to the formation of dihydrophenanthrenic structures. Such an electrocyclisation is of course not possible with an ethane spacer, thus justifying the non observation of stabilised photomerocyanines with $\mathbf{C h r}$ - 
Et-Chr. A classical opening-closing reaction of this one, producing TT isomer, was observed.

The thermal evolution of dihydrophenanthrenic structures was very slow. Two pathways were observed: conversion to initial compound, with the reclosing of photomerocyanines and poor decyclisation. In contrast, dihydrophenanthrenic molecules were bleached to form phenanthrenic structures, thus leading to the loss of photochromic properties. Nevertheless, this oxidative phenomenon was less favourable when a naphthopyran entity was present.

Degassing the samples made it possible to retrieve initial structures more or less rapidely. And so, Spo-ZSpo was retrieved. In contrast, the reforming of SpoZ-Chr was not the main process. Equilibrium between both TTC-D-TC and TTC-D-TT naphthopyrans was observed.

\section{ACKNOWLEDGMENTS}

The $300 \mathrm{MHz}$ NMR facilities were funded by the Région Nord-Pas de Calais (France), the Ministère de la Jeunesse, de l'Education Nationale et de la Recherche (MJENR) and the Fonds Européens de Développement Régional (FEDER). Part of this collaborative work was performed within the framework of the "Groupe de Recherche: Photochromes Organiques, Molécules, Mécanismes, Modèles”, GDR CNRS n² 2466.

\section{REFERENCES}

[1] N. Y. C. Chu, in Photochromism: Molecules and Systems, (H. Dürr and H. Bouas-Laurent, Eds.), Elsevier, Amsterdam, 1990, pp. 493-879.

[2] S. Maeda, Organic Photochromic and Thermodynamic Compounds, (J. C. Crano and R. J. Guglielmetti, Eds.), Kluwer Academic/Plenum Publishers, New York, 1999, p. 85.

[3] B. Van Gemert, Organic Photochromic and Ther- mochromic Compounds, (J. C. Crano and R. J. Guglielmetti, Eds.), Kluwer Academic/Plenum Press, New York, 1999, p. 111.

[4] N. Y. C. Chu, Can. J. Chem. 61 (1983), 300.

[5] R. S. Becker and J. Michl, J. Am. Chem. Soc. 88 (1966), 5931.

[6] V. Lokshin, A. Samat, and A. V. Metelitsa, Russ. Chem. Rev. 71 (2002), 893.

[7] A. Samat, V. Lokshin, K. Chamontin, D. Levi, G. Pepe, and R. Guglielmetti, Tetrahedron 57 (2001), 7349.

[8] S. Delbaere, C. Bochu, N. Azaroual, G. Buntinx, and G. Vermeersch, J. Chem. Soc., Perkin Trans. 2 (1997), 1499.

[9] S. Delbaere, J.-C. Micheau, Y. Teral, C. Bochu, M. Campredon, and G. Vermeersch, Photochem. Photobiol. 74 (2001), 694.

[10] S. Delbaere, J.-C. Micheau, J. Berthet, and G. Vermeersch, Intern. J. Photoenergy 6 (2004), 151.

[11] J. Berthet, S. Delbaere, D. Levi, A. Samat, R. Guglielmetti, and G. Vermeersch, Photochem. Photobiol. Sciences 1 (2002), 665.

[12] J. Berthet, S. Delbaere, V. Lokshin, C. Bochu, A. Samat, R. Guglielmetti, and G. Vermeersch, Photochem. Photobiol. Sciences 1 (2002), 333.

[13] J. Berthet, S. Delbaere, D. Levi, P. Brun, R. Guglielmetti, and G. Vermeersch, J. Chem. Soc., Perkin Trans. 212 (2002), 2118.

[14] F. Ortica, D. Levi, P. Brun, R. Guglielmetti, U. Mazzucato, and G. Favaro, J. Photochem. Photobiol. A: Chem. 138 (2001), 123.

[15] F. Ortica, D. Levi, P. Brun, R. Guglielmetti, U. Mazzucato, and G. Favaro, J. Photochem. Photobiol. A: Chem. 139 (2001), 133.

[16] M. Irie, Chem. Rev. 100 (2000), 1685.

[17] S. Delbaere, J. C. Micheau, and G. Vermeersch, J. Org. Chem. 68 (2003), 8968.

[18] K. A. Muszkat, Top. Curr. Chem. 88 (1980), 89. 


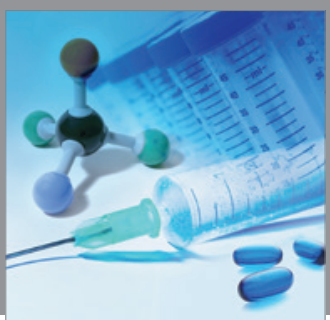

International Journal of

Medicinal Chemistry

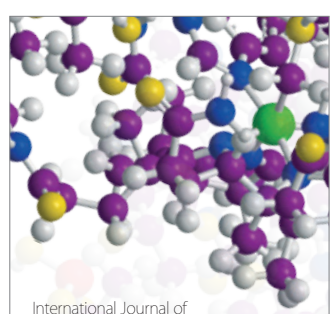

Carbohydrate Chemistry

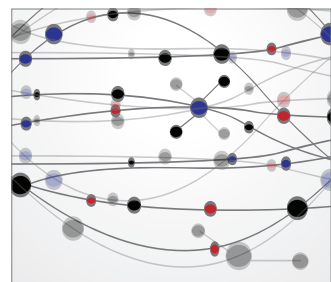

The Scientific World Journal
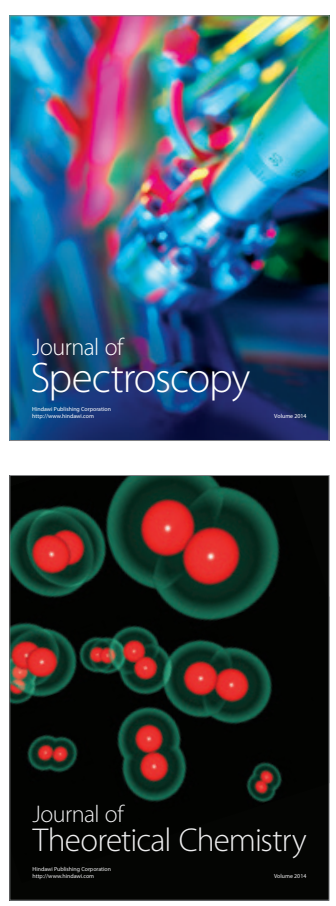
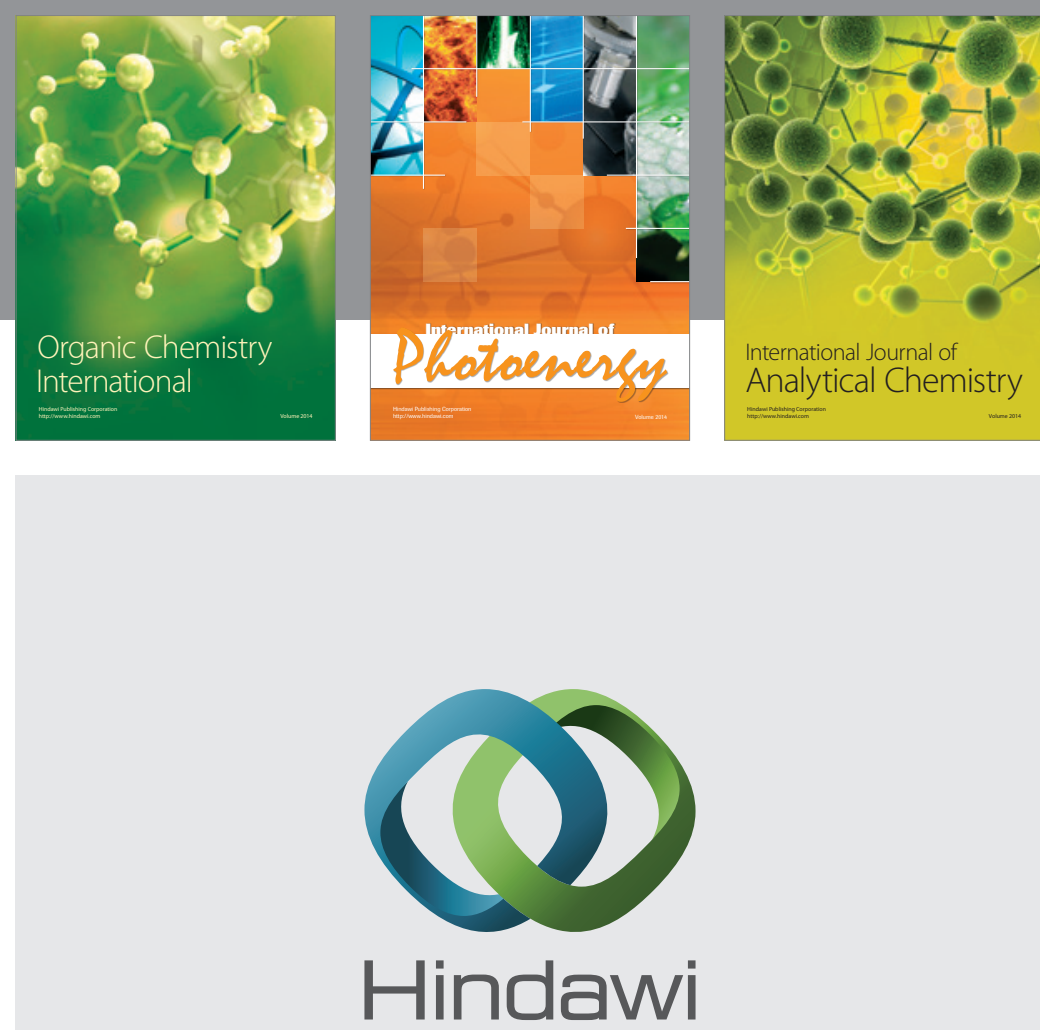

Submit your manuscripts at

http://www.hindawi.com
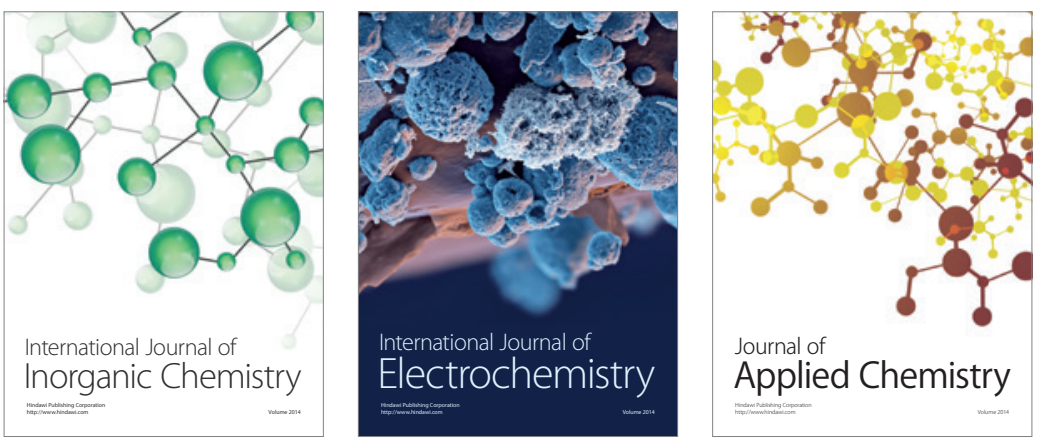

Journal of

Applied Chemistry
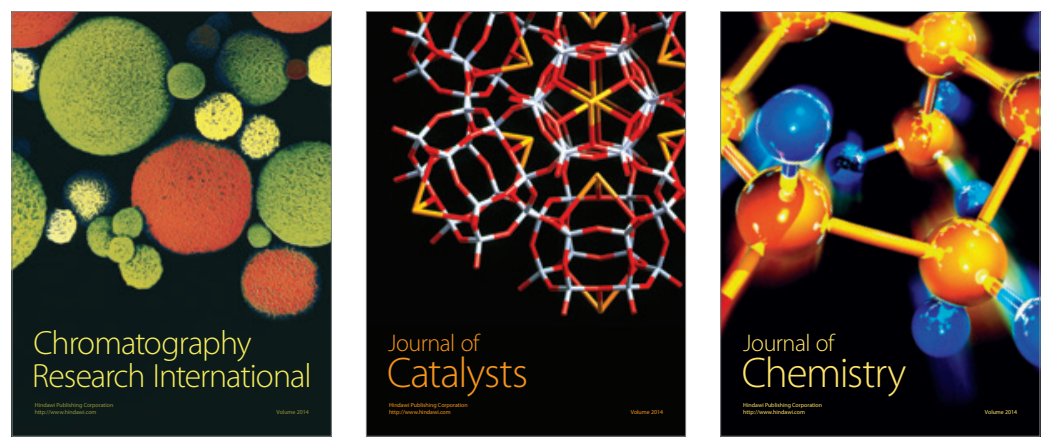
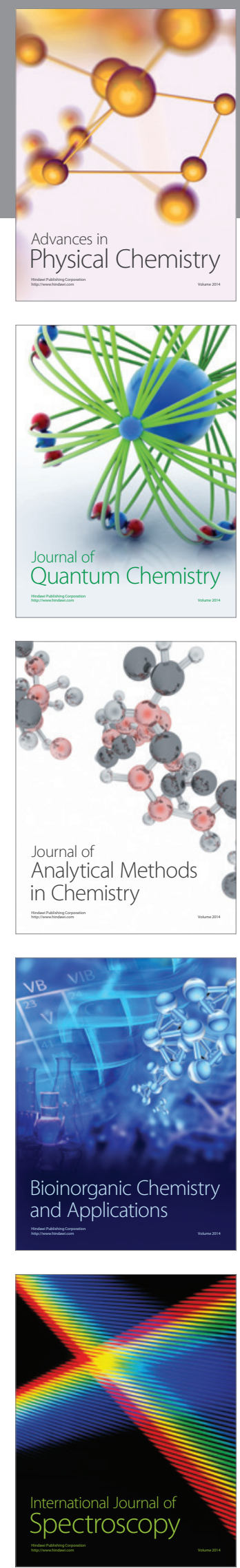